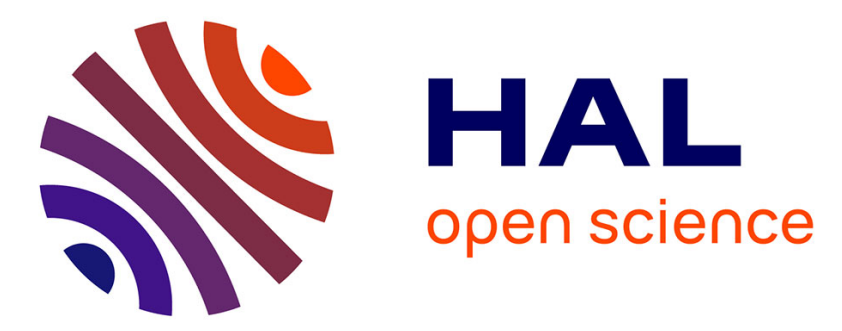

\title{
On the human exposure to radio frequency radiations expected from future small connected objects
}

Dinh-Thuy Phan-Huy, Yvan Kokar, Thierry Sarrebourse, Nadine

Malhouroux-Gaffet, Patrice Pajusco, Christian Leray, Azeddine Gati, Joe

Wiart

\section{To cite this version:}

Dinh-Thuy Phan-Huy, Yvan Kokar, Thierry Sarrebourse, Nadine Malhouroux-Gaffet, Patrice Pajusco, et al.. On the human exposure to radio frequency radiations expected from future small connected objects. GLOBECOM workshops 2014, Dec 2014, Austin, United States. pp.1186-1191. hal-01115809

\author{
HAL Id: hal-01115809 \\ https://hal.science/hal-01115809
}

Submitted on 19 Feb 2015

HAL is a multi-disciplinary open access archive for the deposit and dissemination of scientific research documents, whether they are published or not. The documents may come from teaching and research institutions in France or abroad, or from public or private research centers.
L'archive ouverte pluridisciplinaire HAL, est destinée au dépôt et à la diffusion de documents scientifiques de niveau recherche, publiés ou non, émanant des établissements d'enseignement et de recherche français ou étrangers, des laboratoires publics ou privés. 


\title{
On the human exposure to radio frequency radiations expected from future small connected objects
}

\author{
Dinh-Thuy Phan-Huy ${ }^{1}$, Yvan Kokar ${ }^{2}$, Thierry Sarrebourse ${ }^{1}$, Nadine Malhouroux-Gaffet ${ }^{1 *}$, Patrice Pajusco ${ }^{3}$, Christian \\ Leray $^{4}$, Azeddine Gati ${ }^{1}$ and Joe Wiart ${ }^{1}$ \\ ${ }^{1}$ Orange Labs, Issy-Les-Moulineaux, France, dinhthuy.phanhuy@ orange.com, \\ ${ }^{1 *}$ Orange Labs, Belfort, France, nadine.malhouroux@orange.com, \\ ${ }^{2}$ INSA, IETR, UEB, Rennes, France, yvan.kokar@insa-rennes.fr, \\ ${ }^{3}$ Télécom Bretagne: Lab-Sticc, Brest, France, patrice.pajusco@telecom-bretagne.eu. \\ ${ }^{4}$ Time Reversal Communications, Cergy-Pontoise, France, christian.leray@time-reversal-communications.fr
}

\begin{abstract}
This paper investigates the human exposure to radio frequency radiations expected from future connected objects. The paper focuses on small objects of around ten centimeters. The study takes into account very recent advances on the design of compact antenna arrays. The specificities of the physical layer of wireless communication standards such as Orthogonal Frequency Division Multiplex waveform and Multiple Input Multiple Output techniques are also taken into account. The Specific Absorption Rate is measured for an object using time reversal based spatial focusing (or equivalently Maximum Ratio Transmission beamforming) as a multi-antenna technique and 8 port micro-structured antennas or 8 port patch antennas as compact antenna solutions.
\end{abstract}

Keywords-component; 5G, connected objects, internet-ofthings, human exposure, micro-structured antennas, MIMO, Specific Absorption Rate.

\section{INTRODUCTION}

The number of objects being connected to the internet is increasing very fast, confirming the emergence of a growing internet of things [1]. More and more of these connected objects are expected to be linked to the internet through a wireless interface rather than a cable or a physical connection. This motivates the current research on the future $5^{\text {th }}$ generation $(5 \mathrm{G})$ air interface to put significant efforts on the particular case of machine type communications [2]. Small connected objects, typically with a size of ten centimeters or a little bit more, are expected to be close to the human body.

In parallel, the concern for the human exposure to the radio frequency radiations from future networks is growing. Consequently, the assessment and the measurement of the level of this exposure is becoming a major research topic [3].

Many studies have already been conducted on the specific absorption rate (SAR) induced by mobile phones and laptops [4-6] in the human head or body. Some of these studies even take into account the last advances in signal processing. For instance, the orthogonal frequency division multiplexing (OFDM) waveform and multiple-input multiple-output (MIMO) techniques, which are bricks of the physical layer for wireless local area networks (WLAN) and $4^{\text {th }}$ generation $(4 \mathrm{G})$ standards $[7,8]$ have been taken into account in [9][5,6]. All these study show that the measured levels of radiations satisfy the standardized requirements.
However, the emerging research topic of compact antenna arrays [10] may change these current conclusions. Due to the coupling effect between antennas, the number of conventional antenna ports that can be packed on a device is limited by the wavelength. As the gain from MIMO techniques increase with the number of uncorrelated antenna ports, the research on compact MIMO antenna arrays [10] is growing. In [10-12], an example of compact multi-port antenna solution has been proposed, that enables to pack up to 8 ports on small objects of ten centimeters. Theoretical and experimental studies conducted in [11-14] have confirmed that these compact solutions based on microstructured antennas or patch antennas do exhibit the capacity gain due to the use of MIMO. The diagrams of these new antennas are far from being omni-directional and exhibit strong lobes in some angular directions. One can wonder whether these new types of antennas designed for small objects and likely to be close to the body, could induce a larger SAR. However, examples of studies [15] on the impact of new antennas on the SAR value, in general, are quite rare.

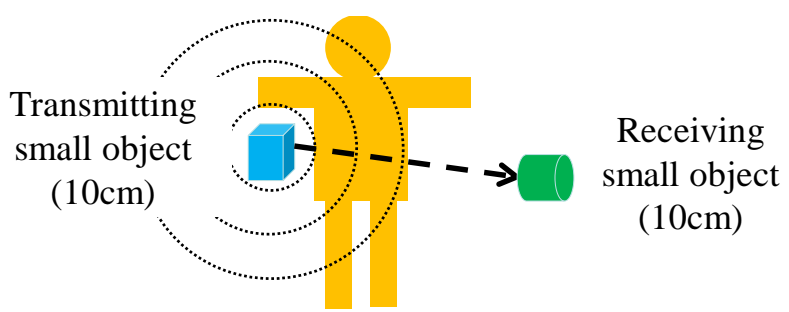

human exposed to radio frequency radiations

Fig. 1 Human exposure to radio frequency radiations due to a close small connected object

In this paper, we propose to estimate the SAR induced by a connection between two objects, when the transmitting object is of small dimension (in the order of ten centimeters), closed to the body, using a compact multi-port antenna solution such as the ones described in [11-14], and using using OFDM and MIMO.

Among all the MIMO techniques, we will investigate a low complexity technique that is time reversal based focusing [15-16]. This technique enables a transmitter to focus the radiated energy towards a target receiver, simply by 
using the time inverse of the channel impulse response as a pre-filter. Thanks to the focusing, the transmitter can lower its transmit power and save some energy, and still deliver the right signal to noise ratio at the receiver. Time reversal technique has also another advantage: the signal received at the receiver is pre-equalized (the distortions due to the multipath propagation channel are partially mitigated). As a consequence, lower complexity receivers can be used. Time reversal has therefore been identified as a new paradigm for green and low complexity wireless communications [17] and more recently especially for green and low complexity Internet of Things [18]. Time reversal technique is equivalent to maximum ratio transmission (MRT) beamforming [19] when it is combined with OFDM [20]. We will use this beamforming scheme to transmit several data streams simultaneously. We will also investigate transmit diversity [9], which is the simplest multi antenna scheme. The SAR will be measured according to the guidelines specified in [21].

The paper is organized as follows. Section II presents the system we are studying. Section III presents our measurement setup and measurement methodology. Section IV presents measurement results. Section V concludes this paper.

\section{SYSTEM DESCRIPTION}

This section presents the wireless communication system we want to assess in terms of SAR.

\section{A. Global system view}

As illustrated in Fig. 2, we consider the transmission between a transmitter object equipped with $N_{t}$ antenna ports and a receiver equipped with $N_{r}$ antenna ports. The transmitter object is supposed to be close to a human subject. The paper aims at evaluating the SAR induced by the transmitter object when it is transmitting data towards the receiver, with all its $N_{t}$ antennas being activated.
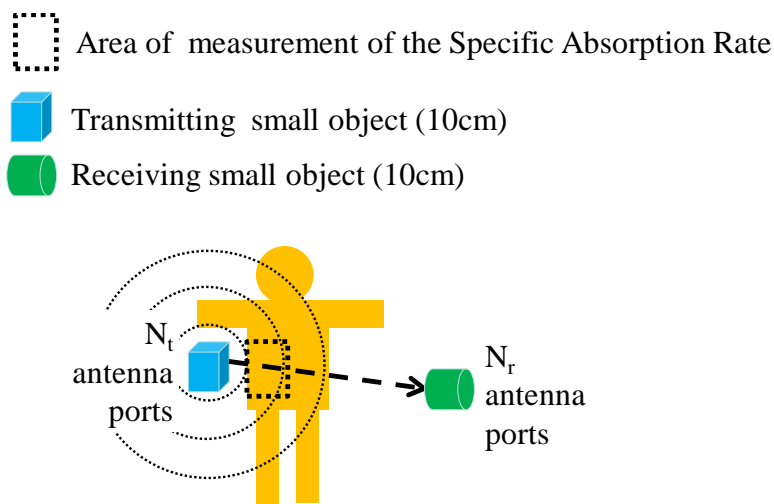

human exposed to radio frequency radiations

Fig. 2 Human exposure to radio frequency radiations due to a close small connected object

Regarding the physical layer, time division duplex mode (TDD), OFDM waveform and MIMO transmission based on channel state information at the transmitter side is assumed, following the same principles as for $4 \mathrm{G}$ and WLAN standards [7,8]. The system is transmitting $N_{r}$ data streams simultaneously, using spatial multiplexing.

Our system processes data on a sub-carrier basis, and can therefore be described mathematically for any sub-carrier independently. For a given sub-carrier, the propagation channel between the transmitter and the receiver can therefore be modeled as a complex $N_{r} \times N_{t}$ matrix $\mathbf{H}$.

During the uplink frame, the transmitter object sends pilots in the uplink and the transmitter object estimates the channel $\mathbf{H}$. Let $\widehat{\mathbf{H}}$ be the estimate of $\mathbf{H}$. This is the so-called 'channel state information at the transmitter' side. The transmitter uses $\widehat{\mathbf{H}}$ to compute the precoding matrix $\mathbf{P}$.

During the downlink frame, the transmitter object sends a transmit vector $z=\mathbf{P} x$, where $x$ is the $N_{r} \times 1$ vector of data symbols to be sent simultaneously. On the receiver side, the $N_{r} \times 1$ receive data vector $y$ is post processed to determine the receive data vector $x^{\prime}$.

Fig. 3 illustrates our system model.

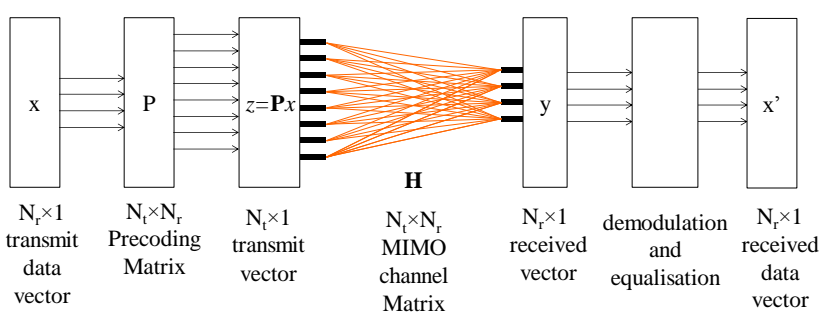

Fig. 3. Physical layer description

In this paper, we focus on the signal output by the transmit object, which is the main source of radiation. We will therefore not detail the behavior of the receiving object. In this paper, the receiving object will be mainly used to send pilot signals as described in the next sub-section.

\section{B. Studied multi-antenna schemes}

In this section, we describe the two transmission schemes being studied in this paper: time reversal based focusing and transmit diversity.

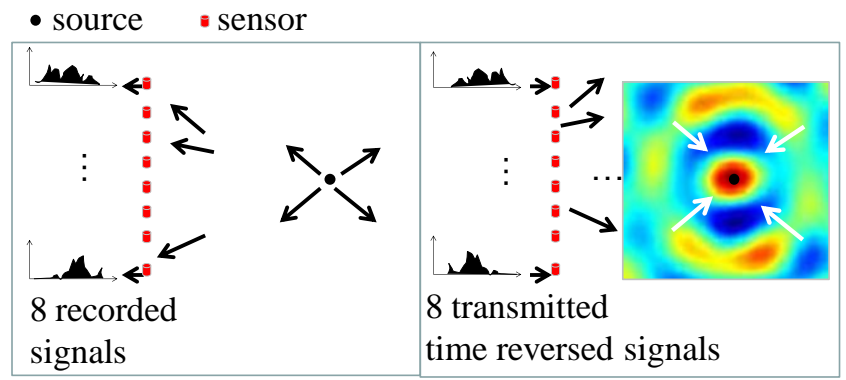

a) Learning phase

Fig. 4. Time reversal principle, single source case

b) Focusing phase

Fig. 4 recalls the principle of time reversal [15-16]. During a learning phase, a source sends a signal and a network of synchronized sensors records the received signals. During a focusing phase, later on, the sensors play their recorded signals time reversely and synchronously. The 
resulting wave propagates back to the source with a higher power at the source than elsewhere.

As illustrated in Fig. 5 spatial focusing is achieved. Fig 5 illustrates the case where the principle is applied to 4 different sources. In this case, the transmitter focuses on 4 sources. This technique is particularly interesting to achieve a higher target signal to noise ratio at the target source, under a constrained transmit power budget.

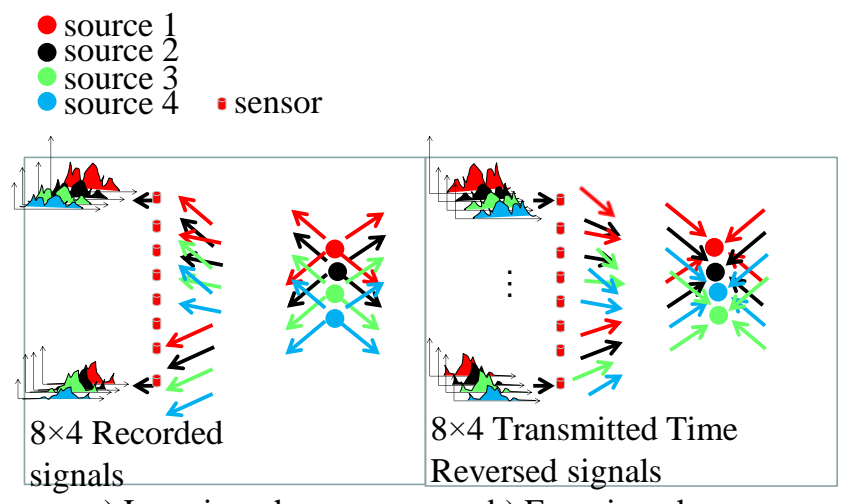

a) Learning phase

b) Focusing phase

Fig. 5. Time reversal principle, multiple sources case

In a wireless communication system using OFDM, as the one being studied in this paper, the learning phase corresponds to the uplink phase where the receiver sends pilots and the transmitter estimates the channel $\mathbf{H}$ to compute the precoder $\mathbf{P}$ and the focusing phase corresponds to the data transmission phase, the time-reversal operation is equivalent to using MRT precoder [19][20]. The single source case is equivalent to the MISO scenario and the multiple sources case is equivalent to the MIMO scenario with spatial multiplexing of as many data streams as receive antennas. Using the previous notations, it is equivalent to using as a precoder, the $N_{t} \times N_{r}$ matrix $\mathbf{P}$ :

$$
\mathbf{P}=\alpha \widehat{\mathbf{H}}^{H}
$$

Where $\mathbf{H}^{H}$ is the transpose conjugate of $\mathbf{H}$ and $\alpha$ is a scalar normalizing factor. Our system is designed such that the time-average power $p$ allocated to one data stream and one transmit antenna port is a constant. With this configuration, the total radiated power $P_{\text {total }}$ is therefore:

$$
P_{\text {total }}=N_{r} N_{t} p
$$

As $p$ is constant, $P_{\text {total }}$ increases with $N_{r}$ and $N_{t}$.

For the special case of $N_{r}=1$, we propose to study transmit diversity, which is even simpler than time reversal. Keeping the same notations, we simply have, in this case:

$$
\mathbf{P}=\alpha \mathbf{A},
$$

where $\mathbf{A}$ is a matrix full of 1 's.

\section{Studied compact multi-port antenna solutions}

In this sub-section we briefly present three examples of compact multi-port antenna solutions, which have all a size of around ten centimeters. For further details on their characteristics (feeding, ground plane, exact dimensions etc...) and performance, please refer to [11-14].
The first solution, as illustrated in Fig. 6, is an 8 port system based on two pairs of patch antennas, each antenna supporting two different polarizations. One pair of patches is on the front face of the antenna, with ports P1, P2, P5 and P6 radiating in the front. The other pair of patches is on the back of the antenna, with ports $\mathrm{P} 3, \mathrm{P} 4, \mathrm{P} 7$ and $\mathrm{P} 8$ radiating in the back.

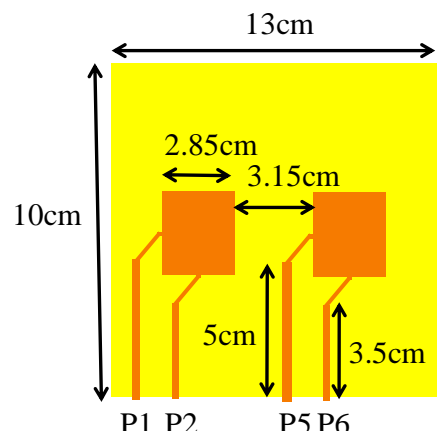

a) front

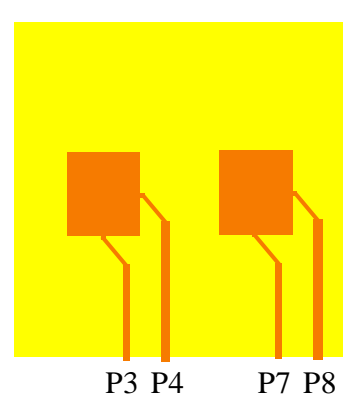

b) back
Fig. 6.8 port patch antenna

The second studied solution, as illustrated in Fig. 7, is a 4 port micro-structured antenna. The ports are inserted into a micro-structure constituted of metallic and conductive slots. The four ports radiate in four different directions which are roughly forming a cross along the surface.

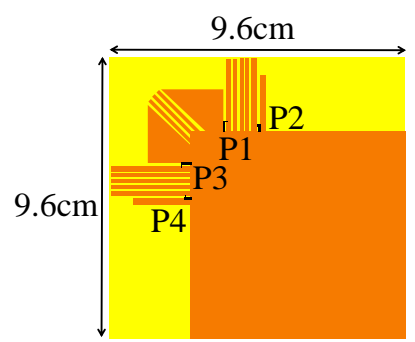

Fig. 7. 4 port micro-structured antenna (ports in black)

The third studied solution, as illustrated in Fig. 8 , is an 8 port micro-structured antenna, which roughly radiates along 8 different directions. The ports P1, P2, P3 and P4 are similar to the ports of the 4 port micro-structured antenna, whereas the ports P5, P6, P7 and P8 (positioned at the 'roots' of the 'teeth') are new.

The two first solutions are flat, whereas the third one has some sorts of 'teeth' and is slightly less compact.

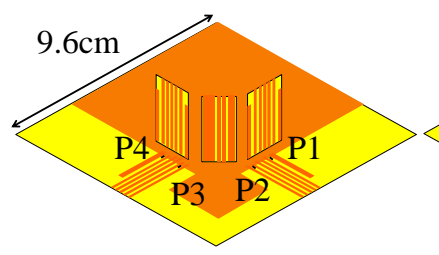

a) front view

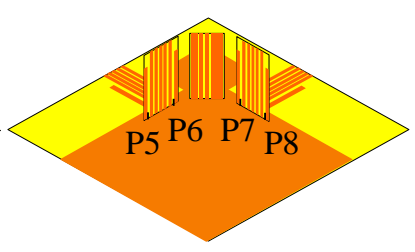

b) back view
Fig. 8.8 port micro-structured antenna (ports in black)

\section{MEASUREMENT METHODOLOGY AND SET-UP}

In this section, we describe our methodology and our test bed for the measurement of the SAR in $10 \mathrm{~g}$ (as defined in [21]). We mainly follow the procedure depicted in [21]. 


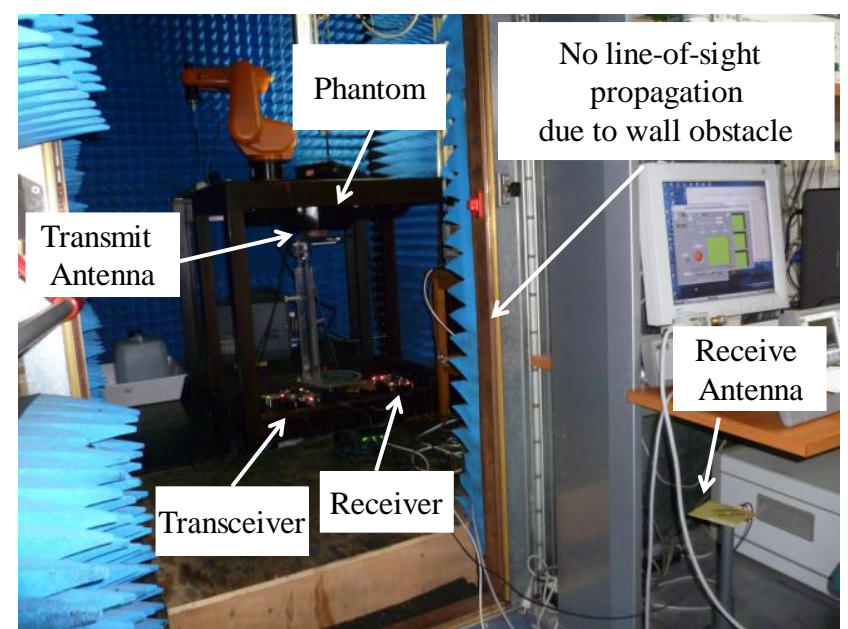

Fig. 9. Measurement setup

Regarding the measurement setup, which is illustrated in Fig. 9, a phantom is used to emulate a human body. The antenna is placed at 3 to 5 millimeters from the phantom. As shown in [22] and [23], for the special case of planar waves, there is a strong impact of the angle of incidence of the waves on the SAR. As a precaution we have therefore first tested several positions of the antennas with respect to the phantom and then selected the positions that maximize the SAR value. The receiver is placed at approximately 2 meters from the transmitter, in a non line-of-sight configuration. This is intended to be as much as possible representative of a typical indoor environment.

Regarding the methodology, we apply the superposition principle depicted in [24]. More precisely, the SAR induced by each transmit antenna port for each data stream is measured individually and stored. Then the $N_{r} N_{t}$ measurements are sums up. One can note that this methodology is valid for measurements near the transmit object as the $N_{r} N_{t}$ signals are likely to be un-correlated random signals and therefore add up together in power. On the contrary, if we had measured the SAR nearby the receiver this methodology would not be longer valid, as signals arrive at the receiver coherently and therefore add up in amplitude.

Regarding the measurement time, data are transmitted during a duration $T$ which is chosen long enough to avoid summed errors due to $N_{r} N_{t}$ measurements to be too large [25]. We recall that the error margin for such types of measurements is in the order of $20 \%$. below.

The main parameters of the setup are listed in the table

TABLE I: MAIN SYSTEM PARAMETERS

\begin{tabular}{|l|c|}
\hline \multicolumn{1}{|c|}{ Parameter } & Value \\
\hline Carrier frequency & $2.4 \mathrm{GHz}$ \\
\hline System bandwidth & $33,4 \mathrm{MHz}$ \\
\hline Sub-carrier spacing, number of sub-carriers & $156,25 \mathrm{kHz}$, \\
& $214 / 256$ \\
\hline Averaging time for measurement $T$ & 20 minutes \\
\hline
\end{tabular}

Regarding the antenna configurations, three different antenna configurations are tested which are listed hereafter.

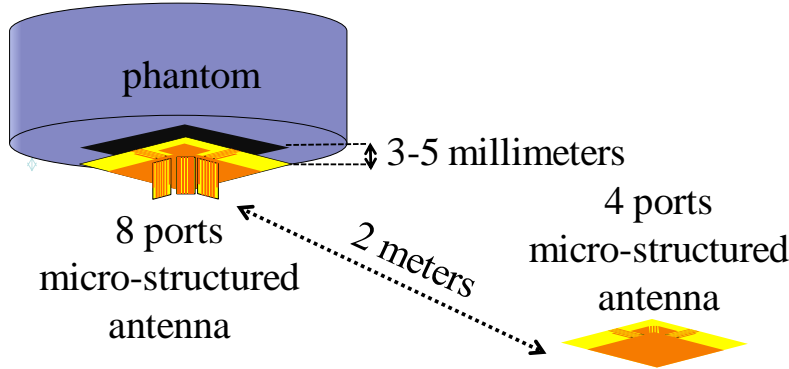

Fig. 10. Antenna configuration A

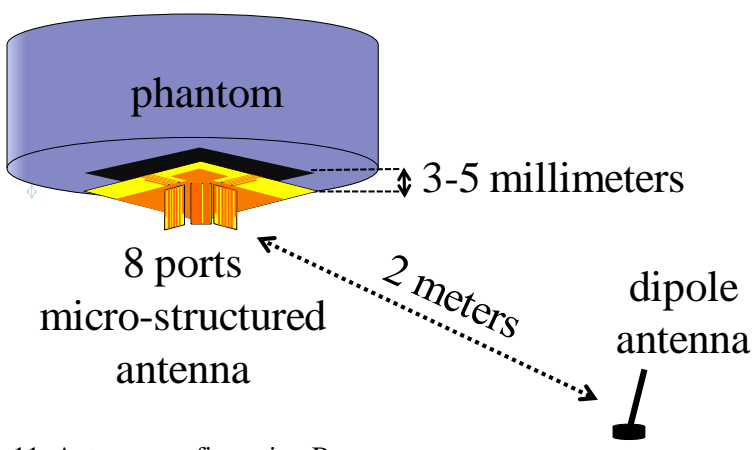

Fig. 11. Antenna configuration B

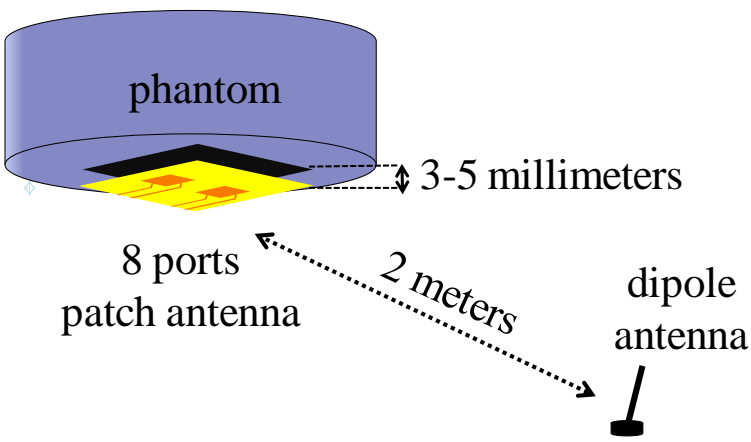

Fig. 12. Antenna configuration $\mathrm{C}$

In the configuration $A$, illustrated in Fig. 10, the transmitter uses an 8 port micro-structured antenna $\left(N_{t}=8\right)$, the receiver uses a 4 port micro-structured antenna $\left(N_{r}=4\right)$. This configuration cumulates the maximum number of streams, and therefore allows us to evaluate the SAR induced by the system when it is operating at its highest power regime: around $18 \mathrm{dBm}$. This value is in the order of current mobile phones emissions (around $20 \mathrm{dBm}$ [26]).

In the configuration $\mathrm{B}$ and $\mathrm{C}$, illustrated in Fig. 11 and Fig. 12, respectively, the transmitter uses an 8 port microstructured antenna $\left(N_{t}=8\right)$ and a 8 port patch antenna respectively, and the receiver uses a single port dipole antenna $\left(N_{r}=1\right)$. The resulting output power is $P_{\text {total }} \sim 12$ $\mathrm{dBm}$. These two configurations enable us to compare the influence of the antenna design on the SAR value.

\section{MEASUREMENT RESUlTS}

Five different scenarios are tested, which are listed in Table II with their corresponding measured SAR values. 
TABLE II: TESTED SCENARIOS

\begin{tabular}{|l|l|l|l|l|}
\hline Scenario & \multicolumn{1}{|c|}{$\begin{array}{c}\text { Antenna } \\
\text { configuration }\end{array}$} & \multicolumn{1}{|c|}{ Scheme } & $\begin{array}{c}\boldsymbol{P}_{\text {total }} \\
(\mathbf{d B m})\end{array}$ & $\begin{array}{c}\text { SAR on } \\
\mathbf{1 0 g} \\
(\mathbf{W} / \mathbf{k g})\end{array}$ \\
\hline 1 & A & Time Reversal & $\sim 18$ & $0.96+/-0.2$ \\
\hline 2 & B & Time Reversal & $\sim 12$ & $0.28+/-0.06$ \\
\hline 3 & B & $\begin{array}{l}\text { Transmit } \\
\text { Diversity }\end{array}$ & $\sim 12$ & $0.17+/-0.04$ \\
\hline 4 & C & Time Reversal & $\sim 12$ & $0.12+/-0.03$ \\
\hline 5 & C & $\begin{array}{l}\text { Transmit } \\
\text { Diversity }\end{array}$ & $\sim 12$ & $0.18+/-0.04$ \\
\hline
\end{tabular}

The scenario 1, which is the one with the highest output power leads to a SAR of $0.96 \mathrm{~W} / \mathrm{kg}$ which is far below the standardized value of 2 . We have also observed that 0.65 $\mathrm{W} / \mathrm{kg}$ are due to the ports $\mathrm{P} 1, \mathrm{P} 2, \mathrm{P} 3$ and $\mathrm{P} 4$ (i.e. the ports belonging to the flat part of the antenna) whereas only $0.31 \mathrm{~W} / \mathrm{kg}$ are radiated by P5, P6, P7 and P8 (i.e. the ports placed at the roots of the 'teeth' of the antenna).

By comparing scenario 2 to 4 , and scenario 3 to 5 , one can observe that the influence of the antenna design on the SAR is low, even though the radiation patterns of these antennas are known to be different [11-13]. This is due to the fact that in both cases, the 4 ports among the 8 are contributing to the SAR, with equal power $(3 \mathrm{dBm}$ per port and per data stream). For the 8 port patch antenna, these contributing ports are P1, P2, P5 and P6, whereas for the 8 port micro-structured antennas, these contributing ports are P1, P2, P3 and P4.

By comparing scenario 2 with scenario 3 and scenario 4 with scenario 5 , one can also conclude that there is not a large influence of the transmission scheme (either time reversal or transmit diversity) on the SAR value.

\section{CONCLUSions}

In this paper we present some experimental results on the expected specific absorption rate induced by a connected object of reduced dimensions (around ten centimeters) over the human body. The last advances in the physical layer such as orthogonal frequency division multiplexing waveform and multiple input multiple output, and the last advances in antenna design such as compact multi-port antennas are taken into account to better reflect the future connected objects technology. Measurements of the specific absorption rate of a body closed to an 8 port micro-structured antenna transmitting four independent streams at $18 \mathrm{dBm}$ exhibit a specific absorption rate value around 1 , which is far below the maximum authorized value of 2 . A comparison between two different compact antennas (micro-structured antennas and patch antennas) shows no significant difference in terms of induced specific absorption rate. A comparison between two multiple input multiple output techniques (timereversal based focusing and transmit diversity) shows no significant difference either. We therefore conclude that the human exposure to radio frequency radiations induced by connected object using the emerging technology of compact multi-port antennas is not large.

\section{ACKNOWLEDGMENT}

This work has been done in the scope of ANR VERSO 2010 TRIMARAN project, and "Pôle Images et Réseaux".

\section{REFERENCES}

[1] Zorzi, M.; Gluhak, A.; Lange, S.; Bassi, A., "From today's INTRAnet of things to a future INTERnet of things: a wireless- and mobilityrelated view," IEEE Wireless Communications, vol.17, no.6, pp.44,51, December 2010.

[2] Osseiran, A.; Braun, V.; Hidekazu, T.; Marsch, P.; Schotten, H.; Tullberg, H.; Uusitalo, M.A.; Schellman, M., "The foundation of the mobile and wireless communications system for 2020 and beyond: Challenges, enablers and technology solutions," in Proc. 2013 IEEE 77th Vehicular Technology Conference (VTC Spring), pp.1,5, 2-5 June 2013.

[3] Tesanovic, M.; Conil, E.; De Domenico, A.; Aguero, R.; Freudenstein, F.; Correia, L.; Bories, S.; Martens, L.; Wiedemann, P.; Wiart, J., "The LEXNET project: Wireless Networks and EMF: Paving the Way for Low-EMF Networks of the Future," IEEE Vehicular Technology Magazine, IEEE, vol. no.99, pp.1.

[4] Shi, D.; Gao, Y.; Du, X. "The SAR value analysis of LTE terminals," in Proc. 2012 International Symposium on Electromagnetic Compatibility (EMC EUROPE), pp.1,4, 17-21 Sept. 2012

[5] Zhao, K.; Zhang, S.; Ying, Z.; Bolin, T.; He, S. "SAR study of different MIMO antenna designs for LTE application in smart mobile phones," in Proc. 2012 IEEE Antennas and Propagation Society International Symposium (APSURSI), pp.1,2, 8-14 July 2012.

[6] Guterman, J.; Moreira, A.A.; Peixeiro, C.; Rahmat-Samii, Y., "User interaction with antenna arrays in MIMO-enabled laptops," in Proc. 3rd European Conference on Antennas and Propagation (EuCAP 2009), pp.226,230, 23-27 March 2009.

[7] 3GPP Technical Specification Group Radio Access Network; Evolved Universal Terrestrial Radio Access (E-UTRA), "Physical Channels and Modulation (Release 10)", TS 36.211, december 2012.

[8] IEEE Standard for Information technology--Local and metropolitan area networks--Specific requirements--Part 11: Wireless LAN Medium Access Control (MAC) and Physical Layer (PHY) Specifications - Amendment 8: Medium Access Control (MAC) Quality of Service Enhancements," IEEE Std 802.11e-2005 (Amendment to IEEE Std 802.11, 1999 Edition (Reaff 2003), pp.1,212, Nov. 112005 .

[9] Gesbert, D.; Shafi, M.; Da-shan Shiu; Smith, P.J.; Naguib, A., "From theory to practice: an overview of MIMO space-time coded wireless systems," IEEE Journal on Selected Areas in Communications, vol.21, no.3, pp.281,302, Apr 2003.

[10] Browne, D.W.; Manteghi, M.; Fitz, M.P.; Rahmat-Samii, Y., "Experiments With Compact Antenna Arrays for MIMO Radio Communications," IEEE Transactions on Antennas and Propagation, vol.54, no.11, pp.3239,3250, Nov. 2006.

[11] Lerosey, G.; Leray, C.; Lemoult, F.; de Rosny, J.; Tourin, A.; Fink, M., "Hybridization band gap based smart antennas: Deep subwavelength yet directional and strongly decoupled MIMO antennas," 2012 6th European Conference on Antennas and Propagation (EUCAP), pp.2697,2701, 26-30 March 2012.

[12] Lerosey, G.; Leray, C.; Lemoult, F.; de Rosny, J.; Tourin, A., "Compact MIMO antenna arrays using metamaterial hybridization band gaps," in Proc. 2012 International Symposium on Antennas and Propagation (ISAP), pp.774,777, Oct. 29 2012-Nov. 2012.

[13] Lerosey, G. ; Leray, C.; Lemoult, F. ; de Rosny, J.; Tourin, A.; Fink, M., "Hybridization band gap based smart antennas: Deep subwavelength yet directional and strongly decoupled MIMO antennas," in Proc. 6th European Conference on Antennas and Propagation (EUCAP 2012), 26-30 March 2012, pp.2697, 2701.

[14] Malhouroux-Gaffet, N.; Pajusco; P., Burghelea, R.; Leray, C. "Capacity Gain of MIMO Systems with Microstructured Antenna Arrays," in Proc. EUCAP 2014, 6-11 april 2014, The Hague, The Netherlands. 
[15] Bonev, I.B.; Barrio, S. C D; Franek, O.; Pedersen, G.F., "A modified metamaterial inspired antenna solution for reduction of the Specific Absorption Rate in the head," in Proc. 2011 International Conference on Electromagnetics in Advanced Applications (ICEAA), pp.769,772, 12-16 Sept. 2011.

[16] A. Derode, A. Tourin, J. de Rosny, M. Tanter, S. Yon, and M. Fink. Taking advantage of multiple scattering to communicate with time reversal antennas. Phys. Rev. Lett., , 2003.

[17] Wang, B.; Wu, Y.; Han, F.; Yang, Y.-H.; Liu, K.J.R., "Green Wireless Communications: A Time-Reversal Paradigm," IEEE Journal on Selected Areas in Communications, vol.29, no.8, pp.1698,1710, September 2011.

[18] Chen, Y.; Han, F.; Yang, Y.-H.; Ma, H.; Han, Y.; Jiang, C.; Lai, H.Q.; Claffey, D.; Safar, Z.; Liu, K.J.R., "Time-Reversal Wireless Paradigm for Green Internet of Things: An Overview," IEEE Internet of Things Journal, vol.1, no.1, pp.81,98, Feb. 2014.

[19] Lo, T. K Y, "Maximum ratio transmission," IEEE Transactions on Communications, vol.47, no.10, pp.1458,1461, Oct 1999.

[20] Dubois, T., Hélard, M., Crussière M; and Germond, C., "Performance of time reversal precoding technique for MISO-OFDM systems", EURASIP Journal on wireless communications and networking, november 2013.

[21] ICNIRP, "Guidelines for limiting exposure to time-varying electric, magnetic and electromagnetic fields (up to $300 \mathrm{GHz}$ ), " Health Phys., vol. 44, pp. 1630-1639, 1998.

[22] Conil, E.; Hadjem, A.; Gati, A.; Man-Fai Wong; Wiart, J., "Influence of Plane-Wave Incidence Angle on Whole Body and Local Exposure at $2100 \mathrm{MHz}, "$ IEEE Transactions on Electromagnetic Compatibility, vol.53, no.1, pp.48,52, Feb. 2011.

[23] Kientega, T.; Conil, E.; Hadjem, A.; Gati, A.; Richalot, E.; Wong, MF; Picon, O.; Wiart, J., "A new approach to assess the Specific Absorption Rate induced by multiple plane waves at $2.1 \mathrm{GHz}$," in Proc. 5th European Conference on Antennas and Propagation (EUCAP), pp.2589,2592, 11-15 April 2011.

[24] Jianxiang Shen; Rui Qiang; Chen, J.; Jackson, D.; Ayatollahi, M.; Yihong Qi; Jarmuszewski, P., "A decomposition/superposition technique for multi-transmitter system SAR measurement," in Proc. IEEE Antennas and Propagation Society International Symposium, 2008 (AP-S 2008), pp.1,4, 5-11 July 2008.

[25] Le, D.T.; Iyama, T.; Hamada, L.; Watanabe, S.; Onishi, T., "Averaging time required for measuring the specific absorption rate of a MIMO transmitter," IEEE Electromagnetic Compatibility Magazine, vol.3, no.1, pp.57,64, 1st Quarter 2014.

[26] ETSI TS 136101 V10.3.0 (2011-06), LTE; Evolved Universal Terrestrial Radio Access (E-UTRA); User Equipment (UE) radio transmission and reception (3GPP TS 36.101 version 10.3.0. 